\title{
DE HISTORIA ATLÁNTICA: UN RECORRIDO POR LOS TEXTOS LATINOS Y ÁRABES MEDIEVALES QUE MENCIONAN LAS ISLAS CANARIAS
}

\author{
José Antonio González Marrero - Maravillas Aguiar Aguilar \\ Instituto de Estudios Medievales y Renacentistas - Universidad de La Laguna \\ toglez@ull.edu.es - maguiar@ull.edu.es
}

Estrabón escribió en lengua griega una Geografía del mundo hasta entonces conocido; la elaboración, metodología y concepción de lo que denomina Mundo Habitado se esboza en su obra como una necesidad para entender lo humano.

Isabel García Gálvez (1986): "Una aproximación...”

\section{RESUMEN}

Las Islas Canarias son un elemento clave en la reconstrucción del conocimiento y la percepción del Atlántico a lo largo de la Edad Media. Encontramos alusiones a las Fortunatae Insulae, al-yazä ir al-jälidät, en un buen número de textos latinos y árabes medievales. En este trabajo presentamos un recorrido por estas fuentes textuales.

Palabras Clave: Islas Canarias, Fortunatae Insulae, al-yazäìir al-jälidät, Descubrimiento, historia atlántica.

\section{ABSTRACT}

«On Atlantic History: An overview of Latin and Arabic medieval texts that quote Canary Islands». The Canary Islands are a key element in the reconstruction of the knowledge and perception of the Atlantic throughout the Middle Ages. Fortunatae Insulae, al-yazä ir al-jälidät are mentioned in a good number of Latin and Arabic medieval texts. In this paper, we expose an overview of those textual sources.

KeY WORDS: Canary Islands, Fortunatae Insulae, al-ŷazä’ir al-jälidāt, Discovery, Atlantic History.

\section{INTRODUCCIÓN}

En 1986, Isabel García Gálvez veía publicado el que creemos fue su primer artículo de investigación. Apareció en el quinto número de la Revista de Filología de la Universidad de La Laguna y en el mismo consignaba todo un planteamiento de investigación básica que se mantendría como uno de sus temas académicos de conversación preferidos: la geografía del mundo antiguo (especialmente los islarios) 
y los múltiples matices de las culturas y los individuos de la historia de la cuenca mediterránea.

Estrabón, nos decía García Gálvez en el citado artículo, fue "autor de su propia biografía... En la descripción del Mundo Habitado según Estrabón, él mismo nos habla de su lugar de nacimiento", de "avatares de indole personal y familiar". Geógrafo griego nacido probablemente en el 63 a.C., señala en su Geografia un dato último, la muerte del rey Juba II, en el año 23 d.C., lo que permite señalar con García Gálvez que "la vida de Estrabón transcurrió durante todo el reinado de Augusto y la primera parte del reinado de Tiberio." La Geografia habría sido elaborada por Estrabón en los primeros años de la Era Cristiana a partir de fuentes eminentemente griegas (García Gálvez, 1986: 199 y ss.). El libro tercero de la Geografía de Estrabón está considerado como el documento etnológico sobre la Hispania Antigua más importante de toda la Antigüedad (Blázquez, 1977: 43). Gracias a esta fuente se sabe que la costa atlántica mauritana era zona de pesca para los gaditanos. Menciona, además, las islas de los Bienaventurados, pero localizándolas en Cádiz, aunque dice de ellas que son "las islas situadas no lejos de la extremidad de Mauritania, que está enfrente de Cádiz...".

Es evidente que las Islas Canarias son un elemento clave en la reconstrucción del conocimiento y la percepción del Atlántico a lo largo de la Edad Media. Las Canarias estuvieron consideradas hasta la Era de los descubrimientos como el extremo occidental de la Ecúmene antigua, es decir, la tierra más extrema en occidente alejada de la tierra conocida. Sabemos que al menos desde el siglo VII a. C. los fenicios ya se habían establecido en la costa atlántica, al sur de Marruecos, concretamente en Mogador ${ }^{1}$. En el siglo V a. C. los cartagineses, continuadores de los fenicios en la colonización y explotación comercial del Mediterráneo Occidental, organizaron dos expediciones para explorar el Atlántico norte y sur. Las expediciones pretendían recopilar información útil para el comercio minero y pesquero. El almirante Hanón fue el encargado de dirigir la expedición a lo largo de la fachada atlántica africana ${ }^{2}$, expedición en la que descubriría las Islas. Las Canarias fueron posteriormente exploradas y colonizadas por Juba II, rey de Numidia y luego de Mauritania, hacia el año

* Estas páginas están dedicadas a nuestra compañera Isabel García Gálvez y pretenden ser un recuerdo de tantas conversaciones de pasillo y despacho acerca de las culturas que en el pasado convivieron en la cuenca mediterránea. Es un trabajo realizado en el marco del proyecto FFI2014-56462-P, La ciencia en Europa en torno a la Era de los Descubrimientos: la construcción de un nuevo enfoque del saber en Astronomía y Navegación (textos árabes, latinos y españoles), financiado por el Ministerio de Economía, Industria y Competitividad.

${ }^{1}$ Str., III, 5, 5; Vell., Hist. Rom., I, 2,3.

${ }^{2}$ Véase J. Ma Blázquez, 1977, "Las Islas Canarias en la Antigüedad". 
25 a. C., hijo de Juba I, rey de Numidia derrotado por Julio César en Tapso, e impulsor del comercio de Mauritania por todo el Mediterráneo (pescado, grano, higos, uvas, madera y, sobre todo, el tinte púrpura para las togas senatoriales) $)^{3}$.

Conocidas por los árabes a través de la obra de Ptolomeo, las llamaron al$\hat{y} a z a ̄$ ir al-jälidät ('las islas eternas'), nombre que procede de la idea subyacente en

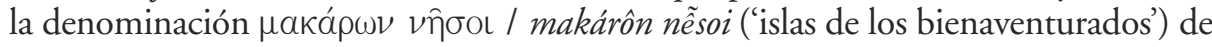
Plinio y otros autores griegos. También las llamaron Fortunātašs, adaptación fonética del nombre latino Fortunatae insulae que se documenta en Sertorio, Estacio Seboso o Plinio el Viejo. Los distintos mitos que explicaban la existencia de un lugar feliz donde las almas de los antepasados y las de los héroes encontraban su descanso, cobraron una existencia geográfica real en forma de islas: Afortunadas, Junonias... Y así como a Marcos Martínez y a Isabel García Gálvez les fascinaron tales repliegues de la mitología griega, otros investigadores también se han interesado por los orígenes míticos, culturales y reales de las Canarias. Se trata sin duda de un tema de interés que ha dado lugar a la publicación de un buen número de estudios a partir de las fuentes griegas, latinas y árabes: Serra Ràfols (1949); Vernet (1971); Lewicki (1983); Viguera (1992); Martínez Hernández (1991, 1992, 1996, 1998, 1999, 2001, 2006, 2010 y 2011); Delgado Delgado (1993); Ducène (2002); Aguiar Aguilar (2005, 2008 y 2014); Arcas Campoy (2008); González Marrero (2008, 2010 y 2016) y Rodríguez Wittmann (2013, 2015, 2016 y 2017).

\section{LAS ISLAS CANARIAS \\ EN LOS TEXTOS LATINOS MEDIEVALES}

La expresión escrita derivada del conocimiento de las Islas Canarias se mantuvo, de una forma mítica o real, a lo largo de la Edad Media en los textos latinos. Sin embargo, son muchos los historiadores de la cosmographia u orbis terrae que consideran que los autores que sitúan su producción geográfica a comienzos del período altomedieval latino no poseen un nivel científico suficiente que aporte novedades. Parece que los dos grandes pilares de la historia de la ciencia deben situarse en los extremos del espacio temporal que va desde el mundo clásico al Renacimiento (Holt-Jensen, 2009: 36-38). Y ello se debe, sobre todo, a que solo se ha prestado interés en grandes obras de autores del siglo I como la enciclopédica Naturalis Historia

${ }^{3}$ Véase la excelente tesis doctoral de Alicia García García, Juba II, rey de Mauritania: traducción y comentario de sus fragmentos, dirigida por Marcos Martínez, Antonio Tejera y Fremiot Hernández y defendida en el curso académico 2006/2007 en la Universidad de La Laguna. Publicada por el Servicio de Publicaciones de la ULL y disponible en línea en acceso abierto. 
de Plinio o la Chorographia de Pomponio Mela, la primera descripción en latín del mundo conocido que nos ha llegado.

Salvo la Collectanea rerum memorabilium de Solino, la principal referencia del siglo IV, cuyas fuentes son las dos señaladas anteriormente, no se hace hincapié en otras obras de esta época porque no existe un método con el que plasmar los contenidos de los estudios geográficos. Y no existirá hasta que vean la luz las Etymologiae siue Origines de Isidoro de Sevilla (560-636), ya a comienzos de la Edad Media. La pedagogía de la escuela medieval se encuentra definida por primera vez por este autor en el libro XIII de su vasta enciclopedia, donde explica la ubicación de las tierras y los espacios que ocupan los mares de una manera sencilla con el fin de que pueda ser entendido por cualquier lector ${ }^{4}$.

Aunque la teoría de la obra isidoriana constituye el punto de partida de la descripción geográfica en tanto en cuanto define los elementos que después se van a reflejar en otros textos, a pesar de su relevancia, hay otros tratados, mal llamados menores, anteriores o posteriores al obispo sevillano, que también pueden proporcionar mucha información referida al espacio atlántico medieval relacionado con las Islas Canarias. Los precursores de este tipo de trabajo poco o nada tienen que ver con Isidoro de Sevilla, precisamente por la carencia de método a la hora de transmitir sus conocimientos, en cambio los posteriores a él lo utilizan como fuente principal a la hora de ordenar sus contenidos.

De estos textos nos interesa reflejar el hecho de que dan a entender que la cosmografía era una necesidad para la sociedad. La primera de ellas tiene que ver con el deseo de Roma de conquistar y organizar el mundo. Al parecer, a propuesta de Julio César se eligieron cuatro hombres para medir el mundo conocido, prestando atención únicamente a los puntos cardinales (Nicolet - Gautier Dalché, 1986: 160; Nicolet, 1991: 15-56). Este proyecto se halla en un texto del siglo IV o V, anotado por un estudiante del cosmógrafo Julio Honorio o Julio Orator que conocemos con el título de Cosmographia Iulii Honorii. Riese editó esta obra (1878) y distingue dos recensiones en la tradición manuscrita, A y B, que deben clasificarse en familias atendiendo a sus diferencias, las cuales han sido analizadas hace unos años por Nicolet - Gautier Dalché (1986). El texto que se relaciona con las Islas Canarias es el que tiene que ver con el río Malva. Desgraciadamente, tenemos la impresión de que faltan datos para establecer una localización exacta para este río, pues ambas recensiones muestran discrepancias: en la A puede leerse Fluvius Malva nascitur sub insulas Fortunatas, circuiens extermam partem Mauritaniae, intercludens inter Barbares et Bacuates vergit in mari quod appellatur Columnae Herculis. La B es más explícita

${ }^{4}$ Isid. orig. 13: «In hoc uero libello quasi in quadam breui tabella quasdam caeli causas situsque terrarum et maris spatia adnotauimus, ut in modico lector ea percurrat, et conpendiosa breuitate etymologias eorum causasque cognoscat». 
y dice Fluvius Malva nascitur sub insulas Fortunatas, circuiens includit omnem partem Mauritaniae Caesariensis, intercludens per anguilationem tortuosam, et amplectitur gentes Africanas quinque, id est Nasamones, Baccuates, Garamantas, Bures et Bacuenses. De ambos textos se deduce que nace en el Atlántico, por debajo de las Islas Afortunadas, y atraviesa la Mauritania cesariana, pero la información que proporciona es confusa. Ofrece, eso sí, los datos necesarios para situar las Islas Afortunadas aproximadamente donde se encuentran las Islas Canarias (Modéran, 2003: 99). Para García-Toraño Martínez (2002: 174) este río debe identificarse con el Malvane, en la actualidad Muluya, cercano a Rusadir en Melilla.

A pesar de la importancia que tiene para la historiografía, los Historiarum aduersus paganos libri VII que el lusitano Paulo Orosio (385-c.420) redacta en época similar a la recepción escrita de la Cosmographia ${ }^{5}$, su aportación al conocimiento de unas islas atlánticas identificadas con Canarias es muy breve y simple, pues señala que están tras el estrecho gaditano se hallan las Islas Afortunadas. Estas, junto con el monte Atlas, son el límite más occidental africano: Ultimus autem finis eius est mons Athlans et insulae quas Fortunatas vocant ${ }^{6}$.

La Aethici Cosmographia o Pseudo-Aethicus es, según palabras de Tierney (1969: 27), una ampliación de la Cosmographia Iulii Honorii, aumentada con el libro I, 2 de los Historiarum aduersus paganos libri VII de Orosio. Se trata de los viajes de Ético de Istria que relata un monje llamado Jerónimo en los siglos VII-VIII (Herren, 2004). Entre las Oceani meridani insulae están Capraria y Fortunatae, pero no ofrece otros datos.

Esta literatura identifica las Islas Canarias con las Islas Afortunadas a comienzos de la Edad Media, pero, pocos siglos después, los activos investigadores que enseñan en la Corte carolingia centran su interés por la geografía a través de un amplio abanico de autores, pues disponen en sus scriptoria de la Naturalis Historia de Plinio, la Chorographia de Pomponio Mela, la Collectanea rerum memorabilium de Solino, la Cosmographia Iulii Honorii, los Historiarum aduersus paganos libri VII de Orosio o las Etymologiae siue Origines de Isidoro de Sevilla, por citar algunos ejemplos. Ello significa que incorporan a sus tratados la bibliografía de la Antigüedad clásica, pero también obras de autores cristianos como Orosio o Isidoro.

En este sentido, la obra del monje Dicuil escrita en el año 825 es el vínculo que hay entre la Alta y la Baja Edad Media y, por tanto, el Liber de mensura orbis terrae que escribió en la Escuela palatina, donde impartió sus clases, debe tenerse en cuenta a la hora de valorar la trascendencia de los textos bajomedievales que beben en su mayor parte de las mismas fuentes que el autor británico. El Liber de mensura es el texto de un monje navegante que aporta poco a la cosmografía de la época,

Zangemeister, K. (1882), Orosius: Historiarum aduersum paganos libri VII, CSEL 5, Viena (= Hildesheim, editio maior, 1967).

${ }^{6}$ Oros. hist. 1, 2, 11. 
puesto que es, en gran medida, la compilación de textos anteriores, pues tres cuartas partes de su obra son anotaciones o copias literales de otros autores, entre las cuales se hallan, de forma explícita, las mencionadas más arriba, pues así las refiere el propio autor (González Marrero, 2010: 9)7 .

Este libro es realmente importante, porque el texto de Dicuil es un retrato que procede en parte de Isidoro de Sevilla, como él mismo señala ${ }^{8}$. Las Afortunadas, Gorgadas y Hespérides se encuentran al oeste de África. Más cercanas a este continente se encuentran las Afortunadas, a continuación las Gorgadas, que están a dos días de navegación de tierra firme, y por último las Hespérides, en el mar de occidente:

Fortunatae atque Gorgodes Hesperidesque insulae quod sunt in occidentali pelago Africae multi nuntiant. Longius ab Africa Gorgodes quam Fortunatae ac Hesperides quam Gorgodes, quoniam in eo quod in Cosmographia fluuius Malua sub insula Fortunata nasci fertur, ex hoc prope ad Africam esse perhibetur. Distant autem Gorgodes a continente terra bidui nauigatione, ut in cuarto decimo libro Aethimologiarum Isidorus ait ${ }^{9}$.

Unos capítulos más adelante, Dicuil vuelve a hacer referencia a las islas y les da nombres que Martínez Hernández (1992b y 1996) ha identificado con las actuales Islas Canarias. Dicuil copia de forma literal el texto de Solino, quien ya había renovado a partir del pasaje de Plinio el viejo ${ }^{10}$. La obra de este es la referencia de todas las informaciones ulteriores relacionadas con las Islas Afortunadas, porque recaba y compara la información que le viene de Estacio Seboso y Juba ${ }^{11}$.

...ferulae surgunt ad arboris magnitudinem; earum quae nigrae sunt expressae liquorem reddunt amarissimum, quae candidae, aquas remouunt etiam potui accommodatas. Alteram insulam Iunoniam appellari ferunt pauxillae edis ignobiliter ad culmen fastigatam. Tertia huic proximat eodem nomine, nuda per omnia. Quarto loco Capraria appellatur, enormibus lacertis plus quam referta. Sequitur Niuaria aere neboloso et coacto ac propterea semper niualis. Deinde Canaria repleta canibus forma eminentissimis, unde etiam duo exhibiti sunt lubae regi. In ea aedificiorum durant uestigia. Auium magna copia, nemora pomifera, palmeta cariotas ferentia, multa nux pinea, larga mellatio, amnes siluris piscibus abundantes. Perhibent etiam expui in eam undoso mari beluas; deinde cum monstra illa putredine tabefacta sunt, omnia illic infici tetro odore ideoque non penitus ad nuncupationem sui congruere insularum qualitatem.

${ }^{7}$ Las ediciones de esta obra (Walckenaer, 1807; Letronne, 1814; Parthey, 1870) han ido centrándose en distintos aspectos hasta llegar a un completo estudio de fuentes en la última (Tierney, 1967).

${ }^{8}$ Isid. orig. $14,6,8-10$.

${ }^{9}$ Dicuil, Liber de mensura, VII, 5.

${ }^{10}$ Plin. nat. 6, 31-32.

${ }^{11}$ González Marrero (2010: 81) analiza la laguna que existe en este punto en la edición de Tierney (1967). 
Dicuil finaliza diciendo que esta información procede de sus lecturas de obras que posee, pero señala que no ha leído que existan otras islas al oeste y al norte de Hispania. Ello confirma que los viajes del geógrafo irlandés partieron de las Islas Británicas y su destino se halla en las islas del norte (Howlett, 1999: 127-134): In occidentali uel septentrionali mari Hispaniae insulas fieri non legimus.

El último de los pequeños textos que queremos reseñar de los que han pasado desapercibidos para la mayor parte de los estudiosos de la ciencia geográfica es el Situs orbis terre uel regionum. Esta obra, concebida para enseñar geografía, no pretende profundizar en todo el mundo que puede percibir el hombre del siglo IX, sino mostrar un mundo heredado, el que otros habían conocido y descrito en la Antigüedad $^{12}$. Al contrario que el Liber de mensura, caracterizado por pinceladas de un tiempo nuevo desde un punto de vista científico, serio y personal, aunque plagado de referencias anteriores, el Situs orbis es el producto de un maestro que necesita un manual para instruir y educar a un alumnado.

Es difícil precisar la fecha en la que fue escrito y tampoco los especialistas se ponen de acuerdo, pues Vernet (1957: 28-29) y Boshof (1969: 321) toman distintos momentos del siglo IX, pero Gautier (1982-1983: 159), apoyándose en el interés que la cultura cristiana tuvo en los siglos VII y VIII por la geografía, supone que este manuscrito fue copiado de uno anterior redactado entre los siglos VII y IX. Una prueba de esto último es que las fuentes de las que se sirve son las Etymologiae siue Origines de Isidoro de Sevilla y el primer libro de los Historiae aduersus paganos libri septem de otro hispano, Orosio. De ambas copia de manera literal en muchas ocasiones. Pero es muy importante reseñar en este caso que el método isidoriano de enseñanza de geografía se encuentra totalmente implantado como modelo escolar en la Corte carolingia. Los textos en que el anónimo autor del Situs orbis se refiere a las islas atlánticas que podemos relacionar con Canarias son:

1. Fortunatarum insulae uocabulo suo significant omnia ferre bona, quasi felices et beate fructuum, uberate enim sua abte natura preciosarum pomma siluarum parturiunt. Fortuitis uitibus iuga collium uestitur. Ad herbarum uice messis et olus uulgo est. Site sunt in oceanum contra leuam Mauritanie, occiduo proxime et inter se interiecto mari discrete... ${ }^{13}$.

Además, en esta ocasión, el autor del Situs orbis corrige el texto de su fuente y elimina un pequeño pasaje, probablemente porque el propio Isidoro de Sevilla considera "el error de los paganos y de los poetas que consideraron que estas islas

${ }^{12}$ El texto latino Situs orbis terre uel regionum ocupa los ff. 1-13v del ms. lat. 4841 de la BNF y fue editado por Gautier Dalché (1982-1983), pp. 149-179.

${ }^{13}$ En este caso Situs orbis terrae, 9, 6, se corresponde con Isid. orig. 14.6.8. 
eran el paraíso" (Vnde gentilium error et saecularium carmina poetarum propter soli fecunditatem easdem esse Paradisum putauerunt).

2. Vltimus autem finis eius est mons Atlans et insule quas Fortunatas uocant ${ }^{14}$.

El uso de la mención que Orosio hace de las islas atlánticas que se hallan frente a la cosa africana es un calco que utiliza en el capítulo dedicado a África.

\section{LAS ISLAS CANARIAS \\ EN LOS TEXTOS ÁRABES MEDIEVALES}

Las Islas Afortunadas, las Islas Eternas de las que nos hablan las fuentes griegas

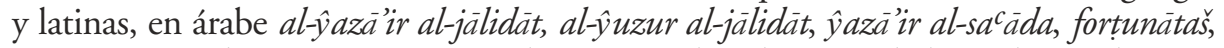
son mencionadas en una treintena de textos árabes distintos de los siglos IX al XVII ${ }^{15}$. Las referencias a las Islas Canarias que se conservan en estas fuentes contienen datos que en su mayoría parecen no proceder de informaciones directas sino de fuentes grecolatinas que los árabes asimilaron y fueron transmitiendo. Ya iniciado el siglo XVII, el bien conocido historiador nacido en Tremecén al-Maqqarī (n. 1578-m. 1632) aún hablaba de unas islas llamadas eternas (jälidät), citando como fuente a Ibn al-Wardī (m. 861/1457), pero es importante tener en cuenta que muchas obras de tema geográfico recogieron mitos, leyendas, sin que ello sea prueba de que Canarias no se conociera como algo real. No obstante, algunas de estas fuentes aportan datos más concretos acerca de las Islas lo cual indica sin duda un conocimiento real y empírico de las mismas. En este sentido el caso más conocido es el texto que el gran Ibn Jaldūn incluyó en su Muqaddima ${ }^{16}$. Anterior es el pasaje que descubrimos en una obra de hagiografía del siglo XIII en el que se narra la misión del santo sufí marroquí Abū Yahyya al-Să’ih en el siglo XII a unas islas del Atlántico ${ }^{17}$. El contenido del texto de Abū Yahya al-Sā'ih permite observar desde una nueva perspectiva el interés de figuras importantes de la religiosidad marroquí de época almohade por extender el islam más allá del Magreb, a unas islas con toda probabilidad ya reales para algunos.

${ }^{14}$ En este caso Situs orbis terrae, 5, 5, 13-14, se corresponde con Oros. hist. 1.2.11.

${ }^{15}$ El Prof. Marcos Martínez nos hizo el encargo de investigar este tema. María Arcas Campoy y yo hemos trabajado durante años buscando estos textos sobre las Islas Afortunadas en las fuentes árabes. Hoy tomo el relevo, por deseo de mi querida compañera Marita y ante su inminente jubilación, en esta investigación. Espero cumplir en un plazo de tiempo razonable el encargo de mis queridos maestros Arcas y Martínez. El proyecto está definido en Marcos Martínez, 1999: "Rerum Canariarum Fontes Arabici".

${ }^{16}$ Introducción a la historia universal (al-Muqaddimah), Ibn Jaldūn. Estudio, preliminar y apéndices de Elías Trabulse. 1ª ed., México, Fondo de Cultura Económica, 1977. El pasaje sobre Canarias se encuentra en pp. 168-169.

${ }^{17}$ Véase Aguiar Aguilar, 2005, "La mención a las Islas Canarias en el Taşhawwufilâ rijâl attaSawwuf de Ibn az-Zayyât at-Tâdilî (primera mitad del siglo 7/XIII)”. 
Las fuentes árabes geográficas más antiguas en la que se menciona a Canarias son el Kitäb șürat al-ard (El libro de la apariencia de la tierra) de al-Jwārizmī (n. ca. 780m. ca. 850) y el Kitäb futüh al-buldān (Libro de las conquistas de los países) de Ahmad b. Yahyā al-Balādūīī (m. 297/892). Se trata de dos obras de enfoque diferente pero que mencionan el límite occidental del mundo de acuerdo con la tradición de la Geografía de Ptolomeo. El Kitāb sūrat al-ard (El libro de la apariencia de la tierra $=$ Cosmografia ) es la geografía finalizada por al-Jwārizmī en 833, revisión de la Geografía de Ptolomeo. El Kitäb Futūh al-buldān (Libro de las conquistas de los países) de Ahmad b. Yahyā al-Balādūūī presenta información ordenada por áreas geográficas conquistadas y constituye un documento fundamental para conocer la historia de la expansión del islam, así como la organización administrativa y social de la época.

A partir del siglo 3/IX podemos documentar un buen número de textos en los que se menciona a las Canarias. Ibn Jurdādbih o Jurradadbih (272/885-300/912), autor del primer Kitäb al-masälik wa-l-mamälik, una recopilación de datos sobre caminos y rutas, da paso a los autores del siglo 4/x: Ibn al-Fāqīh al-Hamadān̄ī, Qudāma Ibn Ŷacfar, Ibn Rusta y Al-Mas'ūdī. Al-Bakrī. Del siglo 6/XII, al-Idrīsī (m. 560/1166) y Abū Hāmid al-Garnāṭī (m. 565/1169). Del siglo 7/XIII, Al-Yāqūt (m. 626/1229), al-Tādilī (m. 628/1230-1231), Ibn Sacīd al-Magribī (m. 685/1274) y al-Qazwīnī (m. 682/1283). Del siglo 8/XIV, al-Dimašqī (m. 727/1327), que cita a al-Bakrī al decir que, en el mar circundante, hacia el oeste, hay seis islas frente a

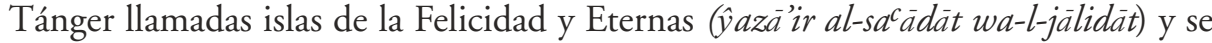
las conoce con el nombre de Frțnāts (Furtunātas). Abū l-Fidā' (m. 732/1331) resume el relato de Ibn Fāțima recogido por Ibn Sậd al-Magribī en el que describe la costa del Atlántico.

Del siglo 9/XV son los textos de Ibn Jaldūn (m. 808/1406) y al-Maqrīzī (1364-1442). El primero de ellos, inspirado en al-Idrīsī e incorporando datos de otras descripciones, se ocupa extensamente de las Islas Eternas en la Muqaddima. Refiere Ibn Jaldūn que, en el primer clima, en la parte occidental, se encuentran las Islas Eternas (al-yazäir al-jälidät) de las que se partió Ptolomeo para marcar las longitudes. Y añade que:

están situadas en el mar Circundante, formando un grupo de islas numerosas, siendo las mayores y más conocidas tres. Se dice que son habitadas. Según tenemos entendido, algunas naves de los francos, habiendo tocado esas islas hacia mediados de la presente centuria, atacaron a los habitantes; los francos lograron botines y llevaron algunos prisioneros, que vendieron unos en las costas del Magreb al-Aqsà. Los cautivos pasaron al servicio del sultán y, al aprender la lengua árabe, dieron datos sobre su isla. Los aborígenes - decían- labraban la tierra con cuernos, el hierro les era desconocido; alimentábanse de cebada; sus ganados se componían de cabras; combatían con piedras, que arrojaban hacia atrás; su única práctica de devoción consistía en prosternarse ante el sol en el momento de su aparición. No conocían ninguna religión, y jamás misionero alguno les llevó alguna doctrina.

Al-Maqrīzī (n. 1364-m. 1442) amplía las noticias sobre Canarias y explica que el sultán benimerín Abū l-Hasan llegó a Ceuta (hacia 740/1339-1340) y allí se encontró con unos marinos genoveses que le contaron que, tras salir de Génova 
con la intención de conocer el mar que circunvala la tierra, pasaron por las Islas Eternas (al-ŷuzur al-jālidāt) cuyos habitantes iban casi desnudos. Y luego, refiriéndose a una sola isla sin indicar su nombre, relató que sus habitantes fueron vencidos y los genoveses la sometieron y la exploraron, comprobando que no existían en ella "más animal que cabras y que araban la tierra con cuernos de cabra para sembrar cebada, único alimento que tienen. No conocen las armas, sólo tiran piedras; dan vuelta al adversario y le arrojan de prisa las piedras. Cuando aparece el sol por el confin del Este, ante él se prosternan". Los genoveses, después de aprovisionarse de agua y haber apresado a algunos isleños, regresaron. Entonces Abū Sālim, el hijo del sultán anterior, recibió como regalo "dos hombres, a quienes puso con su servidumbre para que aprendieran la lengua árabe y así contaron cosas de su situación y decian que las gentes de aquellas islas nunca supieron del islam ni tuvieron de él referencia alguna". Este relato, aunque coincide con el de Ibn Jaldūn, es más detallado ya que, además de otros datos de interés, aparecen la fecha de $740 \mathrm{AH} / 1339 \mathrm{AD}$, el lugar y los nombres de los sultanes que recibieron la información de unos navegantes genoveses que habían estado en las islas Eternas, probablemente al mando de Lanzarotto Malocello (Quartapelle, 2017: 37).

Finalmente, las referencias a Canarias en textos árabes ya en época de la conquista castellana son las de al-Himyarī y la de al-Maqqarī. Al-Himyarī, alfaquí y cadí de origen magrebí fallecido en 900/1494, es el autor del Kitāb al-rawd almít tär fi jabar al-aqțār. Documentamos en esta obra la mención a Canarias como islas del océano, límite de lo conocido. El Nafh al-tiib de al-Maqqarī (m. 986/1577), por su parte, nos cuenta cómo al-Andalus está rodeada de islas o lugares que los árabes llaman islas: "en el Océano hay seis islas, enfrente del pais de los negros, que se llaman Eternas (al-jälidāt). Nadie sabe lo que hay más allả. Según al-Maqqarī las islas Afortunadas (al-sacāadat) están en el océano (üqiyānus), como las islas Eternas (al-jälidāt), y en ellas hay muchas ciudades habitadas por los Mâyūs que son una nación cristiana, nos dice al-Maqqarī, que cultiva las tierras.

\section{CONCLUSIONES}

Los textos de la latinidad clásica que llegan a la Edad Media en forma de códices informan al lector de los mares y las tierras de las tres partes del mundo conocido. Ya Casiodoro aconseja en sus Institutiones dininarum et saecularium litterarum (inst. 25,1) que es tarea de los monjes estudiar y conocer en qué parte del mundo se ubican los lugares que se leen en los Libros Sagrados: mares, islas, montañas famosas, provincias, ciudades, etc., que son la clave para el conocimiento de la cosmografía. Y hace mención (inst. 25,1-2) de célebres autores como Ptolomeo (S. II), tratados como la Cosmographia de Julio Honorio (SS. IV-V), del conde Marcelino (S. VI), o, incluso, del mapa de Dionisio Periegeta (S. II). Ello es una evidencia clara de que las bibliotecas de los monasterios altomedievales preservan obras de carácter geográfico que proceden de la Antigüedad. De ello se deriva también que el interés por los lugares maravillosos del mare ignotum sea un factor indispensable en cualquiera de los textos latinos que llegan a la Corte carolingia. Y este mar desconocido es el 
Atlántico que une el mundo porque rodea todas las tierras, siguiendo las palabras del Situs orbis terrae $(1,2-3)$. La necesidad de reproducir una lista de lugares no es otra que la de transmitir una imagen real, aunque desconocida en muchas ocasiones, del espacio atlántico. En este sentido son significativos pequeños tratados que se han dejado de lado en la investigación geográfica del paso del Mundo clásico a la Edad Media, que en ocasiones, ofrecen puntos de vista propios acerca de las islas atlánticas.

Por otro lado, a lo largo de la Edad Media, la tradición clásica de la ciencia y la filosofía griega fue recogida por la civilización árabe-islámica en distintas etapas. Sabra nos explica que el islam medieval se apropió del legado griego y naturalizó sus contenidos filosóficos y científicos y advierte de que tal proceso - complejo en contenido, actores y cronología - puede analizarse desde distintos puntos de vista atendiendo a la especialidad que aborde la cuestión. Es decir, un historiador o filólogo de la Antigüedad clásica griega estructurará su análisis con el objeto de reconstruir información perdida que no se ha conservado en fuentes griegas (y que sí se ha conservado en fuentes árabes); un medievalista-latinista abordará el objeto de estudio para demostrar cómo el proceso de apropiación-transmisión de las ciencias árabes influyó en el desarrollo de las ciencias en el occidente medieval; y un arabista analizará la cuestión como un fenómeno que se produce en la civilización árabe-islámica y como tal deberá comprenderlo y explicarlo en el contexto de dicha civilización (Sabra, 1987). En cualquier caso, los textos latinos y árabes que hasta ahora sabemos nos hablan de las Islas Eternas demuestran que existe abundante material y en él profundizaremos desde nuevas perspectivas, lo que requiere sin duda un trabajo interdisciplinar.

\section{REFERENCIAS BIBLIOGRÁFICAS}

Aguiar Aguilar, M. (2005): «La mención a las Islas Canarias en el Tašawwuf ilà riŷăl al-tașawwuf de Ibn al-Zayyāt al-Tādilī (primera mitad del siglo VII/XiII)", en J. AguAdé, Á. VicEnTE, L. Abushams (eds.), Sacrum Arabo-Semiticum. Homenaje al Profesor Federico Corriente en su 65 aniversario, Zaragoza, pp. 71-77.

_ (2008): «Políticas de posesión del corredor Atlántico. En torno a las fuentes árabes sobre Canarias en la obra de da Costa de Macedo", en F. Morales PADrón (coord.), Actas del XVII Coloquio de Historia Canario-americana, Casa de Colón, Las Palmas de Gran Canaria, pp. 218-227.

_ (2014): «La navegación en el Atlántico sur en la Baja Edad Media: a propósito de Canarias y la entrada Uqiyānus del Kitäb al-rawd al-micțār fi jabar al-aqțār de Ibn 'Abd al-Muncim alHimyarī (m. 900/1494)», en Mohamed MeouaK, Cristina DE LA Puente (eds.), Vivir de tal suerte. Homenaje a Juan Antonio Souto Lasala, Córdoba, pp. 31-46.

ArCas Campoy, M. (2008): «Les Îles 'Éternelles'/'du Bonheur'/'Fortunées' dans les sources arabes. État de la question et nouvelles perpectives», en K. D’Hulster, J. VAN STEENBERGEN (eds.), Continuity and Change in the Realms of Islam. Studies in Honour of Professor Urbain Vermeulen, Lovaina, pp. 11-24.

Blázquez, J. Ma. (1977): «Las Islas Canarias en la Antigüedad», Anuario de Estudios Atlánticos 23: 35-50 [También en J. Ma BlázQueZ, España Romana, Madrid, 1996, pp. 173-184]. 
Boshof, E. (1969): Erzbischof Agobard von Lyon. Leben und Werk, Colonia-Viena.

Delgado Delgado, J. A. (1993): «De Posidonio a Floro: Las Insulae Fortunatae de Sertorio», Revista de Historia Canaria 177: 61-74.

DUCÈNE, J.-CH. (2002): «Une vraisemblable navigation arabe vers les Canaries au début du III $/ \mathrm{IX}^{\mathrm{e}}$ siècle (Extrait du K. daläill al-qibla d'Ibn al-Qāșș)», Folia Orientalia 38: 105-113.

GARCÍA GÁlVEZ, I. (1986): «Una aproximación a la geografía de Estrabón», Revista de Filología de la Universidad de La Laguna 5: 195-204.

GarCía GarCía, A. (2006/2007): Juba II, rey de Mauritania: traducción y comentario de sus fragmentos. Tesis doctoral publicada por el Servicio de Publicaciones de la ULL [Disponible en línea en acceso abierto: ftp://tesis.bbtk.ull.es/ccssyhum/cs231.pdf (15/05/2018)].

García-Toraño Martínez, A. (2002): Rutilio Namaciano. El Retorno. Geógrafos latinos menores, Gredos, Madrid.

Gautier Dalché, P. (1982-1983): «Situs orbis terre vel regionum: un traité de géographie inédit du Haut Moyen Age (Paris, B. N. Latin 4841)», Revue d'Historie des texts 12-13: 149-179.

GonzÁlez Marrero, J. A. (2008): «Fuentes latinas relacionadas con Canarias en la obra de Da Costa de Macedo», en F. Morales Padrón (coord.), Actas del XVII Coloquio de Historia Canarioamericana, Casa de Colón, Las Palmas de Gran Canaria, pp. 238-248.

(2010): «Las islas atlánticas en el Liber de mensura Orbis terrae del monje geógrafo irlandés Dicuil del siglo IX", Anuario de Estudios Atlánticos 56: 71-90.

(2016): «El espacio atlántico en el siglo IX a través del anónimo Sitvs Orbis Terre vel Regionvm», Anuario de Estudios Atlánticos 62: 1-10.

(2017a): «La navegación por las islas atlánticas a través de las Vitae Sanctorum Hiberniae», en J. F. Mesa SAnZ, Latinidad medieval hispánica, Sismel, Florencia, pp. 263-276.

(2017b): «Nuevos enfoques en la didáctica de la cosmografía en el siglo IX. El Liber de mensura orbis terrae de Dicuil», Revista de Estudios Latinos (RELat) 17: 71-87.

Herren, M. (2004): «The 'Cosmography' of Aethicus Ister: Speculations about its date, provenance, and audience», en A. Bihrer - E. STEIN (eds.), Nova de Veteribus, Múnich, pp. 79-102.

Holt-Jensen, A. (2009): Geography: History and Concepts: a Student's Guide, SAGE Publications, Londres.

Howlett, D. R. (1999): «Dicuil on the Islands of the North», Peritia 13: 127-134.

LETRONNE, A. J. (1814): Recherches géographiques et critiques sur le livre De mensura orbis terrae, Germain Mathiot Libraire, París.

LEWICKI, T. (1983): «Encore sur les voyages arabes au Canaries au Moyen Âge», Études maghrébines et soudanaises 2: 9-31.

Martínez Hernández, M. (1991): "Canarias en la antigüedad: mito y utopía», en F. Morales PADRÓN (dir.), Historia de Canarias, Alzira (Valencia), pp. 21-40.

- (1992a): Canarias en la mitología: historia mitica del archipiélago, Centro de la Cultura Popular Canaria, Santa Cruz de Tenerife.

(1992b): «La onomástica de las Islas Canarias de la Antigüedad a nuestros días», en Actas del $x$ Coloquio de Historia Canario-americana, Cabildo Insular de Gran Canaria, Las Palmas de Gran Canaria, tomo II, pp. 230-278.

(1996): Las Islas Canarias de la Antiguedad al Renacimiento: nuevos aspectos, Centro de la Cultura Popular Canaria, Santa Cruz de Tenerife. 
(1998a): «Estacio Seboso», en A. M. Macías Hernández (dir.), Gran Enciclopedia Canaria, La Laguna-Las Palmas de Gran Canaria, vol. VI, p. 1437.

(1998b): «Fortunatae Insulae», en A. M. MaCíAS Hernández (dir.), Gran Enciclopedia Canaria, La Laguna-Las Palmas de Gran Canaria, vol. vI, pp. 1544-1545.

- (1999): «Rerum Canariarum Fontes Arabici», Revista de Filología de la Universidad de La Laguna 17: 427-439.

(2001): «Boccaccio y su entorno en relación con las Islas Canarias», Cuadernos de Filología Italiana [número extraordinario 8 (La recepción de Boccaccio en España)]: 95-118.

(2006): «Las Islas Afortunadas en la Edad Media», Cuadernos del CEMyR 14: 57-78.

(2010): «Islas míticas en relación con Canarias», Cuadernos de Filología Clásica. Estudios Griegos e Indoeuropeos 20: 139-158.

(2011): «La tradición clásica en la Descripción de las Islas Canarias (1592) de Leonardo Torriani», Fortunatae 22: 117-128.

ModérAn, Y. (2003): Les Maures et l'Afrique romaine (IVe-VII siècle), Bibliothèque des Écoles françaises d'Athènes et de Rome, Roma.

Nicolet, C. (1991): Space, Geography and Politics in the Early Roman Empire, The University of Michigan Press, Ann Arbor.

Nicolet, C. - Gautier Dalché, P. (1986): «Les 'quatre sages' de Jules César et la 'mesure du monde' selon Julius Honorius: réalité antique et tradition médiévale», Journal des savants 4: 157-218.

PARTHEY, G. (1870): Dicuili Liber de mensura orbis terrae, Berlín.

Quartapelle, A. (2017): «El redescubrimiento de las Islas Canarias en el Anno Domini 1339», Revista de Historia Canaria 199: 11-37.

RodríGuez Wittmann, K. (2013a): «El mar verde de la melancolía. Las Islas Canarias en las fuentes medievales (siglos IV-IX)», Medievalismo. Revista de la Sociedad Española de Estudios Medievales 23: 343-358.

- (2013b): «Plinio, Isidoro de Sevilla, Hugo de San Víctor. Referencias interrelacionadas en el conocimiento medieval de Canarias», en R. J. GonzÁlez Zalacain, B. Divassón Mendívil y J. Soler Segura (coords.), Actas de las V Jornadas Prebendado Pacheco de Investigación Histórica, Ilustre Ayuntamiento de la Villa de Tegueste, Tegueste, pp. 68-79.

- (2015): «Descubriendo el velo. El recuerdo medieval de las Afortunadas en los portulanos mediterráneos del XIV», Revista de Historia Canaria 197: 237-261.

- (2016a): Las islas del fin del mundo. Representación de las Afortunadas en los mapas del Occidente medieval, Lleida.

(2016b): «Closest to Where the Sun Sets': The Fortunate Islands and the Limits of the World in Medieval Geography and Cartography», en H. Piercy, A. Richards y A. STEed (eds.), Darkness and Illumination. The Pursuit of Knowledge in the Medieval and Early Modern World, Durham, pp. 63-80.

(2017): «La visión cartográfica del Atlántico en el siglo XVI: notas en torno al ejemplar del Theatrum Orbis Terrarum conservado en el Fondo Antiguo de la Universidad de La Laguna», en Actas del XXII Coloquio de Historia Canario-Americana, Las Palmas de Gran Canaria, pp. 1-15.

Rosenthal, F. (1992 [1975]): The Classical Heritage in Islam, traducción de Das Fortleben der Antike im Islam (Zürich, 1965) por E. and J. MARMORSTEIN, Routledge, London.

SABRA, A. I. (1987): «The Appropriation and Subsequent Naturalization of Greek Science in Medieval Islam: A Preliminary Statement», History of Science 25 (3): 223-243. 
SERRA RÀFols, E. (1949): «Los árabes y las Canarias prehispánicas». Revista de Historia 86-87, t. XV, año XXII: 161-177.

TIERneY, J. (1967): Dicuili Liber de mensura orbis terrae, Dublin Institute for Advanced Studies, Dublín.

Vernet, J. (1971): «Textos árabes de viajes por el Atlántico», Anuario de Estudios Atlánticos 17: 401-427 [También en J. VeRneT, De cAbd al-Raḥmān I a Isabel II. Recopilación de estudios dispersos sobre Historia de la Ciencia y de la Cultura Española ofrecida al autor por sus discípulos con ocasión de su LXV aniversario, Barcelona, 1989, pp. 197-223].

Viguera, Ma. J. (1992): «Eco árabe de un viaje genovés a las Islas Canarias antes de 1340», Medievalismo 2: 257-258.

Walckenaer, C. A. (1807): Dicuili liber de mensura orbis terrae ex duobus codd. Mss Bibliothecae Imperialis, Firm. Didot, París. 